\title{
Analysis of energy usage and examination of renewable energies in a university campus
}

Sanjay Satya-Akunuri Koka, Samuel R. Simpson, Michael C. Young

The University of Toledo, College of Natural Sciences and Mathematics, Department of Chemistry and Biochemistry

\section{Abstract}

According to the United Nations, the current level of emissions of greenhouse gases will result in the global mean temperature of the world to rise above pre-industrial levels by the end of the century. This alarming report suggests that there must be immediate action taken to strengthen education programs related to

sustainable, renewable energies. Educational programs relating to renewable energies are best suited to be

explored at the collegiate level due to the number of resources and best "green" practices that are already
implemented. The University of Toledo is a public university located in northwest Ohio and caters to 20,000

mplemented. The Universly of Toledo is a public universiy located in northwest Ohio and caters to 20,000

students. As a research university, many investments are made in promoting academic scholarship and
research in various topics within Green Chemistry. However, it is important to review the implementation of

research in various topics within Green Chemistry. However, it is important to review the implementation of
Green Chemistry principles, and its relation to more sustainable practices. We observed such implementation

Green Chemistry principles, and its relation to more sustainable practices. We observed such implementatio
on our campus and designed a study based on this observation among the student population to gauge

student knowledge of Green Chemistry and future best practices. Following the collection of these results,

students were exposed to education regarding personal implementation of Green Chemistry techniques,

which they can implement into their lives and continue practicing in the future. We will present our studies,

strategies, and tips to encourage replicate studies on campuses nationwide.

\section{Introduction}

Utilizing Renewable Energies and abiding

with the principles of Green Chemistry on

a college campus is essential towards

building more sustainable practices and

reducing greenhouse gases. This study

explores the current renewable energy

sources constructed by the University of

Toledo, communicates the importance of Green Chemistry to interested students, and finds methods to educate students on the principles of Green Chemistry while also exploring effective laboratory methods efficiency. The project hypothesizes that eftudents will be open to changes in that students will be open to changes in their curriculum to explore Green Chemistry educalton to modules because of immense importance towards the environment. Furthermore, this study is designed to be repeatable so that rese
is encouraged on renewable energy is encouraged on renewable energy
sources on campuses across the world.

\section{Methods}

- Conducted research on the renewable energy sources that are being utilized by the University of Toledo (UToledo). There was access to live data from the Solar Field at UT which was analyzed. Next, UT's use of wind energy in the form of an $80 \mathrm{kWh}$ two-blade and $4 \mathrm{kWh}$ helical wind turbine was studied. Lastly, the information allowed for the analysis of UToledo's cogeneration turbine (generate 260 kilowatts of "clean" electricity)

- To start the project analysis, 100 College of Natural Science and Mathematics (NSM) students were surveyed using a Google platform in order to gather data analyzing their knowledge of the ACS's 12 Principles of Green Chemistry.

- Another survey conducted (utilized Google platform) focused on identifying the most effective educational plan to teach chemistry students about the importance of renewable energies and the principles of Green Chemistry: the survey was sent to NSM students and their answers were recorded.

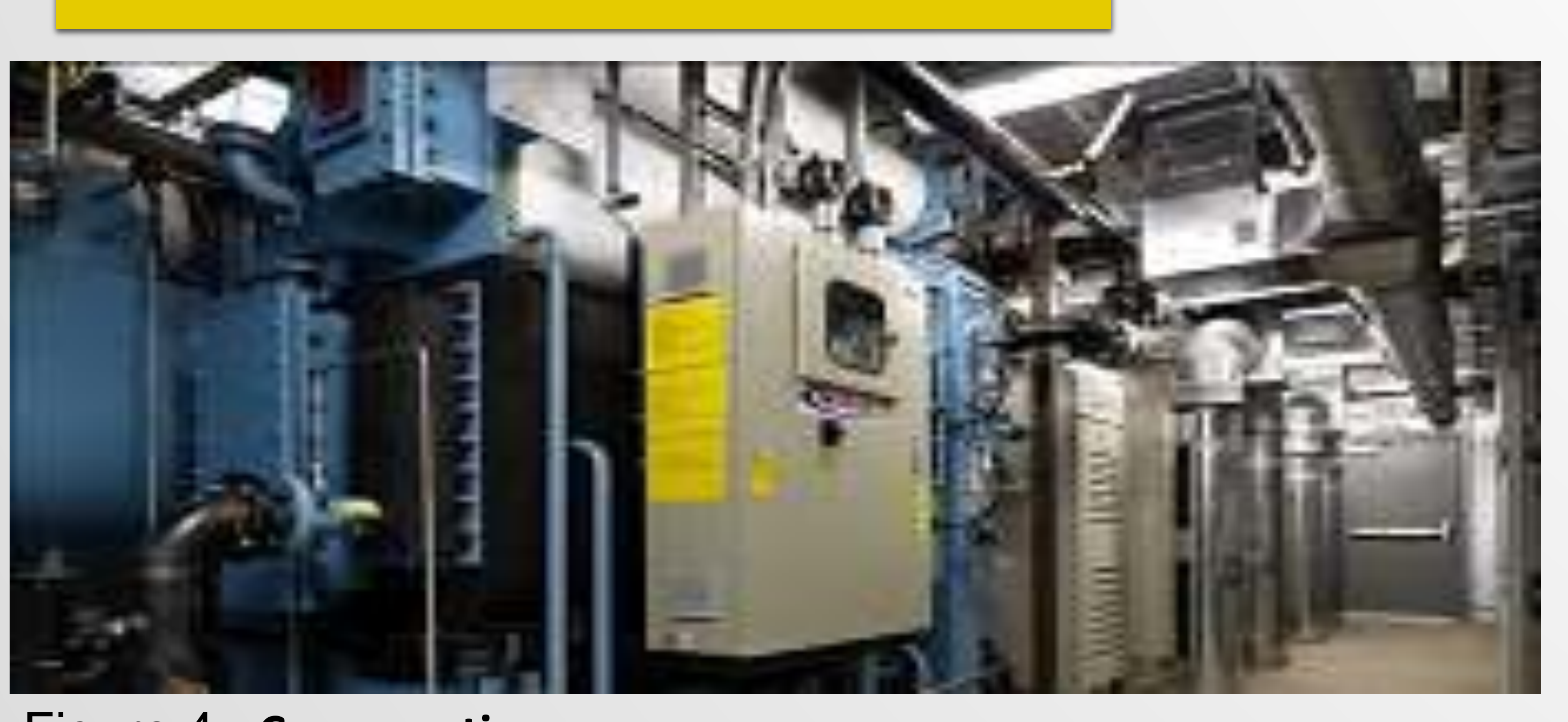

Figure 4 : Cogeneration.

Four natural-gas turbines that spool up to 96,000 revolutions per minute to generate 260 kilowatts of electricity, providing continuous power to the
university's critical data center

\section{References}

\section{Results}

Figure 1-1 illustrates that the majority of the university's STEM student population is not familiar with ACS's 12 Principles of Green Chemistry. After further analysis, it was determined that the chemistry students were able to recognize a few of the principles from their experience in the General Chemistry Laboratory sequence. Most importantly, the initial survey process indicates zero students were aware of all 12 Principles of Green Chemistry. Based off the data collected, there needs to be further education provided in the educational curriculum for students to understand the importance of the 12 Green Chemistry Principles.

Figure 1-2 illustrates UToledo's STEM students favoring an educational plan adhering to the Green Chemistry principles in the form of an online module rather than an in-class module taken during UToledo's General Chemistry requence. This form of education can serve to aid students to realize the importance of implementing the ACS Green Chemistry principles as well as importance of implementing the ACS Green Chemistry principles as well encourage them to conduct research on renewable energies utilized on
college campuses. It is important to further the analysis, so methods can be optimized to educate and encourage students to become involved in renewable energy research and implementation.

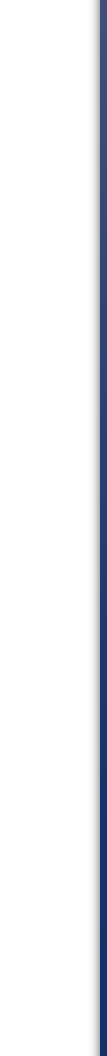

\section{Conclusion}

Now, there is a strong foundation to ensure the continued analysis of Green Chemistry practices in university setting. Clearly, students are interested in implementing safer, more efficient chemistry practices in accordance with the ACS principles of Green Chemistry. The hypothesis that students would be open to changes in their educational curriculum during their laboratory classes was proven correct based off the data collected. The data collected indicates that students were not aware of the renewable sources of energy, such as the wind turbine and cogeneration, that was present on UT's campus and they were did not know the specific principles of Green Chemistry. Therefore, implementing an education system that includes Green Chemistry is a main objective and is an endeavor supported by students at University of Toledo. It is integral to continue our analysis and encourage current scientists to conduct research on renewable sources of energy so that we can build a more efficient, and cleaner environment for future generations.

Saleh, HEDM, Introductory Chapter: Principles of Green Chemistry, IntechOpen

Laird Trevor, Green Chemistry is Good Process Chemistry. Organic Process Research \& Development 201216 (1), 1 -2 